\title{
Cooperative Principle Used by Chris Gardner in "The Pursuit of Happyness" Movie
}

Sapalakkai, C. O.O.

English Department, Faculty of Letters, Petra Christian University, Siwalankerto 121-131, Surabaya 60236, East Java, INDONESIA E-mails: cityoisi10@gmail.com

\begin{abstract}
This study is to find out what maxims are used by Chris Gardner, what maxims are flouted by Chris, and what implicature can be interpreted by flouting the maxims in the business conversation in The Pursuit of Happiness movie. The source of the data was the film and the transcript, and the data were taken from Chris' utterances in the five chosen scenes showing the process of Chris's success in pursuing his happiness in his life. The findings revealed that he mostly followed the maxim of manner and the least was maxim of quality. He also flouted the maxim of quality and the least was maxim of manner. From the flouting of the maxims, there was implicature that could be interpreted which was to create a good relation, to get a good chance, and to fulfill Chris's will to be one employee in Dean Witter Reynolds-Resource Dept. which is the beginning of his success in his life. In conclusion, the flouting of the maxims was part of Chris's effort in his life that gave contribution to his success, and it is proved through Chris' utterances in the five chosen scenes.
\end{abstract}

Keywords: Cooperative principle, Four maxims, Flouting of maxims, Implicature

\section{INTRODUCTION}

Since communication is done in people's everyday life, speakers and listeners must speak cooperatively with each other to be understood in a particular way. In order to make conversation understood by the speaker and the hearer, there must be the general principle of language use, called the cooperative principle (Renkema, 1993). According to Paul Grice (Yule, 2014) the cooperative principle can be divided into four maxims: Maxim of Quality, Maxim of Quantity, Maxim of Relevance and Maxim of Manner. Maxim is a set of norms which language users adhere to in order to uphold the effectiveness and efficience of communication (Hatim and Mason, 1990). Then in communicating, speaker and hearer must obey the four maxims in order to create effective communication. On the other hand, sometimes the maxims are not obeyed, or it can be violated called the flouting of maxim. The flouting of maxims takes place when individual deliberately ceases to apply the maxim to persuade their listener to infer the hidden meaning behind the utterances; creating implicature (S.C. Levinson, 1983) state in Khosravizadeh (2011). Therefore, implicature occurs when a speaker chooses to flout a maxim. Then, by flouting the maxim or not obeying the maxim, people imply something in the conversation. For the purpose, this study is to find out what maxims are used by Chris Gardner, what maxims are flouted by Chris, and what implicature can be interpreted by flouting the maxims in the business conversation in The Pursuit of Happiness movie. The scope of this study is Discourse Analysis, focusing on the four maxims of cooperative principle. By doing this study, the writer hopes that the findings would be useful for readers. The reader can get information about Chris' utterances in communicating that helps him to get a good relation which gives a very big impact for his success in his life through the cooperative principle and the implicature involved

In this study, the writer used the theory on Cooperative Principle proposed by Grice (1975) stated in George Yule (2014) in her data analysis. The cooperative principle is stated in the following way: 
"make your conversational contribute such as is required, at stage at which it occurs, by the accepted purpose or direction of the talk exchange in which you are engaged"(Grice,1975:45). Supporting this principle are the four maxims, often called the 'Gricean maxims' which are maxim of quantity, maxim of quality, maxim of relation, and maxim of manner. On some occasions speakers flout the cooperative principles and intend their hearer to understand this; that is, they purposely do not observe the maxim and intend their hearer to be aware of this (Paltridge, 2006). The flouting of maxims takes place when individual deliberately ceases to apply the maxim to persuade their listener to infer the hidden meaning behind the utterances; creating implicature (S.C. Levinson, 1983) state in Khosravizadeh (2011). According to Brown and Yule (1983) implicature is used to calculate what is suggested and meant by the speaker as a different thing from what he actually said explicitly. With the cooperative principle and the maxims as guides, we can start to work out how people actually decided that someone is 'implying' something in conversation (Yule, 2014).

This research used qualitative approach. Qualitative research involves data collection procedures that result primarily in open-ended, non-numerical data which is then analyzed primarily by nonstatiscally methods (Doernyei, 2007). The source data of this research is the film and the transcript. The data were taken from all of the utterances spoken by Chris Gardner and some relevant characters in the five chosen scenes. They are the taxi scene, the interview scene, the scene at Chris' customer's, the game scene, and the ending scene. In collecting the data, there were some steps that had been done by the writer. They were watching the movie for several and chose the scenes that the writer wanted to analyze. Those scenes show Chris has a conversation with manager of Dean Witter Reynolds Dept., an interview in Dean Witter Reynolds Dept, a business conversation with his valuable customer, and become one employee in of Dean Witter Reynolds Dept. Next, the writer searched for the transcript in the internet and matched the utterances with the film. Lastly, the writer labeled each utterance produced by Chris and some relevant characters in the five chosen scenes by using the system of numbering. The writer used three digits number that helped the writer in labeling the data. The first digit of the number refers to the scene in which there are five scenes that the writer analyzed. The second digit refers to the characters. The third digit refers to the order of utterance from the each character that the writer analyzed.

The analysis is based on the theory of four maxims of co-operative principle proposed by Grice (1975) stated in George Yule (2014). In analyzing the data, the writer identified the context of the conversation. Then, the writer analyzed the function of utterance to find out the type of four maxims of cooperative principles and the followed and flouted maxim, and the implied meaning that can be interpreted behind the flouting of the maxim. The writer gives sign of the plus $(+)$ and minus (-) indicates which maxims are followed and flouted respectively. The writer also gives the abbreviation of the type of four maxim: Qn stands for maxim of quantity, Qi stands for maxim of quality, Rt stands for maxim of relation, and Mn stands for maxim of manner. Lastly, those are analyzed by using the following table.

Table 3.1. Chris Gardner's uses of cooperative principles

\begin{tabular}{|c|c|c|c|c|c|c|c|c|c|c|c|}
\hline \multirow[t]{3}{*}{ Number } & \multirow[t]{3}{*}{ utterances } & \multicolumn{8}{|c|}{ Four maxims } & \multirow[t]{3}{*}{ Implicature } & \multirow[t]{3}{*}{ Note } \\
\hline & & \multicolumn{2}{|c|}{ Qn } & \multicolumn{2}{|c|}{ Qi } & \multicolumn{2}{|c|}{$\mathrm{Rt}$} & \multicolumn{2}{|c|}{$\mathrm{Mn}$} & & \\
\hline & & + & & + & . & + & & + & - & & \\
\hline 1.1.1. & & & & & & & & & & & \\
\hline & & & & & & & & & & & \\
\hline & & & & & & & & & & & \\
\hline & & & & & & & & & & & \\
\hline & & & & & & & & & & & \\
\hline & & & & & & & & & & & \\
\hline
\end{tabular}

Note: - Utterances: a spoken word, statement,

- Qn: Maxim of Quatity $\quad$ - Plus (+): Sign for following the maxim

- Qi: Maxim of Quality - Minus (-): Sign for flouting the maxim

- Rt: Maxim of Relation - Implicature: what is implied from the

- Mn: Maxim of Manner flouting of the maxim 
- Note: The explanation of the flouting of the maxims column

After doing the analysis the writer found out about the maxim followed by Chris and the maxim followed and flouted in the five chosen scenes and the implicature.

\subsection{The maxims followed by Chris Gardner}

After analyzing the data, the writer found out the findings about the types of four maxim used and flouted by Chris Gardner. The result is presented on the following table 4.1.

Table 4.1 The maxims followed and flouted by Chris Gardner

\begin{tabular}{|l|l|l|l|l|}
\hline Principle Cooperative & $\begin{array}{l}\text { Maxim of } \\
\text { Quantity }\end{array}$ & $\begin{array}{l}\text { Maxim of } \\
\text { Quality }\end{array}$ & $\begin{array}{l}\text { Maxim of } \\
\text { Relation }\end{array}$ & $\begin{array}{l}\text { Maxim of } \\
\text { Manner }\end{array}$ \\
\hline Followed & 58 & 48 & 60 & 61 \\
\hline Flouted & 3 & 14 & 2 & 1 \\
\hline
\end{tabular}

Table 4.1. shows the results of the use of maxim in Chris's utterances. It shows that Chris followed the maxim of relation, maxim of manner, maxim of quantity, and maxim of quality. It can be seen from the table that the most maxim followed by Chris is maxim of relation and the least is maxim of quality. The table also shows that Chris flouted the maxims of quality, maxim of quantity, maxim of manner, and maxim of relation. The most maxim flouted by Chris is maxim of quality and the least is maxim of relation. Next, the writer would give some examples of the types of four maxims that are followed and flouted by Chris Gardner. To prove the writer's answer, she would like to give some examples of the maxims followed by Chris.

\subsubsection{Maxim of quantity}

The first maxim of cooperative principle is the maxim of quantity. The quantity maxim: make your contribution as informative as is required, but no more, or less, that is required. One example that shows Chris uses this type of this maxim is from data 2.3.4. and 2.1.5.

Interviewer 1: what were you doing before you were arrested?

Chris: I was painting my apartment.

Here Chris is trying to answer the question of one the interviewers' question about what he does before he arrests that makes him come late to do interview. Here Chris's answer is that he is painting his apartment. His answer is not too much and too little because his answer is based on the question about what he does before he is arrested by police. By saying so, Chris uses and follows the maxim of Quantity. Here Chris gives the answer what is required from the question of the interviewer which Chris does before the police arrest him before the interview.

\subsubsection{Maxim of quality}

The second maxim of cooperative principle is the maxim of quality. The quality maxim: do not say that which you believe to be false or for which you lack adequate evidence. One example that shows Chris uses this type of this maxim is from data 2.1.2 and 2.2.3.

Chris: I've been sitting there for the last half-hour trying to come up with a story that would explain my being here dressed like that. And I wanted to come up with a story that would demonstrate qualities that I'm sure you all admire here, like earnestness or diligence. Team-playing, something and I couldn't think of anything. So the truth is...I was arrested for failure to pay parking tickets.

Jay Twistle: parking ticket?

The conversation happens when Chris comes late to do interview. Here, Chris comes up with explanation why he comes late and looks dirty. He tells a story about the problem that he faces that makes him not have time to prepare himself to do the interview. By telling the story, Chris wants to give evidence and reason why he comes late with inappropriate appearance. Therefore, Chris's utterances show that he follows maxim of quality by telling the truth about why he cannot prepare himself well to do the interview

4.1.3. Maxim of relation 
The third maxim of cooperative principle is the maxim of relation. The relation maxim: be relevant. This maxim is concerned with the relevance of contribution made by speakers in communication exchange. One example that shows Chris uses this type of this maxim is taken from data 1.2.11., 1.1.12., 1.2.13, and 1.1.14.

Jay: I'm sorry. I'm sorry (holding a mess rubic), this thing is impossible

Chris: I can do it

Jay: No, you cannot. No one can. That's bullshit

Chris: No, I'm pretty sure I can do it.

Here Chris and Jay are having conversation in the taxi but Jay is busy in fixing the rubic. Jay believes that the rubic is really impossible to fix, but Chris says that he can fix the mess rubic. Chris thinks it is possible for him to finish, even though Mr. Jay thought it is impossible for many people. It shows that Chris's contribution in the conversation is related to the previous speaker whether he can fix the rubic or not. The conversation shows that Chris follows the maxim of relation because of his being relevance to what the previous speaker talks about.

4.4.4. Maxim of manner

The last maxim of cooperative principle is the maxim of manner. The manner maxim: be clear, brief, and orderly. The maxim of manner requires the speaker to avoid obscurity of expression and ambiguity. One example that shows Chris uses this type of this maxim is taken from data 2.3.8., 2.2.9., 2.3.10., 2.1.11., 2.3.12., 2.1.13, 2.3.14, and 2.1.15.

Martin Frohm: Jay says you're pretty determined.

Jay Twistle: He's been waiting outside the front of the building with some 20 kilos jigger for over a month.

Martin Frohm: He said you're clever.

Chris Gardner: Well, I like to think so.

Martin Frohm: And you want to learn this business?.

Chris Gardner: Yes, sir, I wanna learn.

Martin Frohm: Have you already started learning on your own?

Chris Gardner: Absolutely.

In this scene, Chris is in the process of conversation trying hard to win the interview. Based on the conversation, Chris gives clear answers based on the question of previous speaker. Here, he is being clear with his answer to the interviewer question. His answer is short and it is clear enough to give his contribution in order to answer the question. It shows that he follows the maxim of manner.

\subsection{The Maxim Flouted by Chris Gardner and the Implicature in the Five Chosen Scenes}

The finding from the table 4.2. shows that Chris flouts the Maxim of Quality, Maxim of Quantity, Maxim of Relation, and Maxim of Manner. The most maxims flouted is the maxim of quality and the least is maxim of relation. To prove the writer's answer, she would like to give some examples of the types of four maxims that are flouted by Chris and its implicature from the five chosen scenes. The flouted maxim can be summarized in the following table.

Table 4.2. The flouted maxims in the five chosen scenes

\begin{tabular}{|l|l|l|l|l|l|l|l|l|}
\hline \multirow{2}{*}{$\begin{array}{l}\text { Chosen } \\
\text { scene }\end{array}$} & \multicolumn{9}{|c|}{ Maxims } & Qn & Qi & \multicolumn{1}{l|}{ Rt } & Mn \\
\cline { 2 - 13 } & + & - & + & - & + & - & + & - \\
\hline 1. Taxi scene & 12 & 1 & 8 & 5 & 13 & - & 13 & \\
\hline 2. Interview scene & 11 & 2 & 13 & - & 12 & 1 & 13 & \\
\hline 3. Customer house's scene & 22 & - & 13 & 9 & 21 & 1 & 21 & 1 \\
\hline 4. Game scene & 6 & - & 6 & - & 6 & - & 6 & - \\
\hline 5. office scene & 8 & - & 8 & - & 8 & - & 8 & - \\
\hline
\end{tabular}

Note: Qn: maxim of quantity

Rt: Maxim of relation

Plus (+): Following the maxims

Qi: Maxim of quality

Minus (-): Flouting the maxims 
Mn: maxim of manner

In the first chosen scene, Chris flouts the maxims of quality and maxim of quantity.

1. The flouting of the maxim quality

This happens when Chris gives untrue contribution in the conversation. One example that shows Chris flouted the maxim of quality and its implicature is taken from data 1.1.4., 1.2.5, 1.1.6, 1.2.7., 1.1.8. and 1.2.9.

Chris: Hi. Chris Gardner. Yeah, hi. Listen

Mr. Jay Twistle: What can I do for you?

Chris: I submitted an application for the intern program about a month ago and I would just love to sit with you briefly-

Mr. Jay Twistle: Listen, I'm going to Noe Valley, Chris. Take care of yourself.

Chirs Gardner: Mr. Twistle. Actually, I'm on my way to Noe Valley also. How about we share a ride?

Mr. Jay Twistle: All right, get in.

In this scene, the flouted maxim focuses on the last utterances of Chris. He tells that he has the same direction as Mr. Jay. In fact he does not. By doing so, Chris flouts the maxim of quality by giving untrue contribution to the other participant in the conversation. In the flouting of the maxim quality, there is implicature that can be interpreted. Here Chris wants to imply that he wants to get a chance to speak to Mr. jay and builds a good relation with him. He lies to Mr. Jay, so that he can spend more time to speak to Mr.Jay about his concern about the internship application that he has already applied.

2. The flouting of the maxim quantity

This happens when Chris gives too much contribution in the conversation. One example that shows Chris flouted the maxim of quantity and its implicature is taken from data 1.2.9., 1.1.10. and 1.2.11.

Mr. Jay Twistle: All right, get in.

Chirs Gardner: All right. So when I was in the Navy, I worked for a doctor...... who loved to play golf, hours every day and I would actually perform medical procedures when he'd leave me in the office. So I'm used to being in a position where I have to make decisions and... Mr. Twistle, listen.This is a very important--.

Mr. Jay Twistle: I'm sorry. I'm sorry (holding a rubic). This thing's impossible.

The conversation happens when Chris and Mr. Jay are in the taxi. Here, Chris gives too much contribution and talks too much by telling about what he has already done in the past. In the flouting of the maxim of quantity, there is implicature that can be interpreted. By doing so, Chris wants to imply that he tries hard to get Mr. Jay's attention by explaining his concern and hopes that Mr. jay can hear his concern. He also wants to give more explanation by telling about what he has done in his past to show that he has enough and much experience that shows he is worthy enough to do the internship. That's is why he talks too much and before he comes up with his desire to do the internship.

In the second chosen scene, Chris flouted the maxim of quantity and maxim of relation.

1. The flouting of the maxim of quantity

This happens when the Chris gives too much in the conversation. One example that shows Chris flouted the maxim of quantity and its implicature is taken from data 2.1.1

Chris Gardner: Chris Gadner. How are you? Good moorning. Chris Gardner. Chris Gardner. Good to see you again. Chris Gardner.Pleasure. I've been sitting there for the last half-hour trying to come up with a story that would explain my being here dressed like this. And I wanted to come up with a story that would demonstrate qualities that I'm sure you all admire here, like earnestness or diligence. Teamplaying, something and I couldn't think of anything. So the truth is...I was arrested for failure to pay parking tickets.

The conversation happens when Chris comes late to the interview. Here he flouts the maxim of quantity. He gives a long greeting by mentioning his name several times before he comes up with explanation why he comes late. He also gives too much information by explaining about the reason why he comes late. In the flouting of the maxim of quantity, there is implicature that can be interpreted. By doing so, Chris wants to imply that he does not want to lose his chance after trying so hard to get help from Mr Jay. He 
does want to give up even though he comes with the inappropriate appearances in the interview session. Then in the interview time he gives too much information and some unnecessary contribution so that the interviewer can understand his situation and give him the opportunity. Fortunately, flouting the maxim of quantity helps him to win the interview and get the chance to do the internship in that company

2. The flouting of the maxim relation.

This happens when Chris is being irrelevant in giving contribution in the conversation. One example that shows Chris flouts the maxim of relation and its implicature is taken from data 2.1.1., 2.2.2. and 2.1.3.

Chris Gardner: I've been sitting there for the last half-hour trying to come up with a story that would explain my being here dressed like this. And I wanted to come up with a story that would demonstrate qualities that I'm sure you all admire here, like earnestness or diligence. Team-playing, something and I couldn't think of anything. So the truth is...I was arrested for failure to pay parking tickets.

Mr. Jay Twistle: Parking tickets?

Chris Gardner: And I ran all the way here from the Polk Station, the police station.

The conversation happens when Chris gives explanation to the interviewer in room. His contribution is not related to previous speaker. The previous speaker is still curious about the parking ticket that creates problem for Chris and hopes Chris tells him about the parking ticket. So, here Chris flouts the maxim of relation. In the flouting of the maxim of relation, there is implicature that can be interpreted. By doing so, Chris wants to imply that he wants to give more reason to convince the interviewer that he is good enough to do internship in that company. Fortunately, in the end of the interview, he can win the interview and can do the internship in the company for six months. Therefore, his effort in flouting those maxims in the interview, scene convinces the interviewers and gets the chance to do the internship.

In the third chosen scene, Chris flouted the maxim of quality, manner, and relation.

1. The flouting of the maxim quality

This happens when Chris gives contribution about something to be false. One example that shows Chris flouts the maxim of quality is taken from

3.1.13.,3.4.13., 3.1.14., 3.4.15., and 3.1.16

Chris: I want you to know that do not take that for granted

Mr Ribbon: Oh, come on. What's that?

Chris: Oh, it's an Osteo National bone-density scanner. A company I bought into prior to going to work at Witter. I have a meeting after the game

Mr. Ribbon: you're going to the game

Chris: Possibly. Possibly

In this scene the flouting of the maxim focuses on Chris' utterances that has been underlined. Chris says that there is a meeting that he needs to attend. In fact he does have any meeting to attend. Here, Chris gives untrue contribution telling lie about what he does next to reply to the previous speaker. In doing so, Chris flouts the maxim of quality. In the flouting of the maxim of quality, there is implicature that can be interpreted. By doing so, Chris wants to imply that he does not want to lose this the important chance to speak to Mr. Ribbon because he is already in his house. Then, he mentions about the game because he knows that Mr. Ribbon is heading to the game and hopes they can continue their conversation there. Fortunately, Mr. Ribbon asks them to go together to the game even though Chris does not have seat in the game. Therefore, flouting the maxim helps Chris to get a chance to talk to Mr. Ribbon and continue their business conversation in the game.

2. The flouting of the maxim of manner.

This happens when Chris is being absurd and does not give clear contribution

in conversation. One example that shows Chris flouted the maxim of manner and its implicature is taken from data 3.4.15., and 3.1.16

Mr. Ribbon: you're going to the game

Chris: Possibly. Possibly

Here, Chris flouts the maxim of manner because his answer is not orderly based on the previous speaker. His answer means whether he wants to go to the game or does not. He says yes or no by using the word 
possible. Possible means perhaps (used to indicate doubt or hesitancy).. In the flouting of the maxim of manner there is implicature that can be interpreted. By doing so, Chris wants to imply that he does not want to lose the chance to speak to Mr. Ribbon. If he tells clearly about the truth that he does not go to the game then his chance to continue their business conversation will never happen. Therefore, flouting the maxim makes Mr. Ribbon ask them to go together to the game. This gives opportunity to Chris to tell his business plan to Mr. Ribbon in the game.

3. The flouting of the maxim relation.

This happens when Chris is being irrelevant in giving contribution in the conversation. One example that shows Chris flouts the maxim of relation and its implicature is taken from data 3.5.41., 3.1.42., 3.5.43.3.1.44.,3.5.45., and 3.1.46.

Christopher: Are you okay?

Chirs Gardner : Yeah, I'm fine, Christopher.louts

Christopher ; Does it hurt?

Christopher: I'm fine.

Christopher: Let me see.

Chirs Gardner: Christopher, sit back. Sit back (the car is heading to the game)

This scene shows that Chris is pretending that he gets bitten by a bee. Here, the flouting of the maxim focuses on Chris' utterances when he gives contribution to his son's question. Here Chris flouts the maxim of relation because his answer is not related to Christopher's question. Christopher asks about Chris's condition but Chris directly ell him to sit back. Instead of saying he is fine he said other things not related to his son's question. In the flouting of the maxim of relation, Chris does not want to Christopher to know that Chris is not getting stung by a bee. By doing so he wants to keep others from realizing how desperate his situation really is especially from Mr. Ribbon. In short, Chris gets chance to continue their business conversation in the game. Even though he cannot make the cooperation with Mr. Ribbon, he gets to know Mr. Ribbon's friend and they have good impression about Chris. Therefore, flouting those maxims helps him to get chance in getting more customer that gives the advantage for the progress of his internship.

Then, in the last chosen scene, the ending scene, Chris gets a call from the superior of the Dean Witter Reynolds Dept. There, he tells Chris he needs to go back in that company tomorrow because the next day will be his first day to have the real work in that company. It means Chris is accepted in that company as the real stockbroker in Dean Witter Reynolds Dept. This scene shows the final of the process of Chris's effort in getting his happiness after experienced many difficulties in his life.

In conclusion, as the finding, Chris mostly follows all four maxims and flouts the four maxims in certain context. Flouting the maxim of quantity, quality, relation and manner is part of Chris effort to pursuit his happiness in his life. Firstly, his effort in flouting those maxims helps him to create good impression and relation. Secondly, his effort in flouting those maxims helps him to win the interview session and get the opportunity to do the internship. Thirdly, his effort in flouting those maxims help him to get the advantage for his internship progress. Finally his effort in flouting those maxims makes him became one employee because he is finally hired in the Dean Witter Reynolds-Resource Dept, which is the beginning of his success in his life. Therefore, the flouting of the maxims in Chris' utterances is a part of Chris effort that gives contribution to his success in his life and gives changing in his life with his son to the better one in the future.

Awin Language (2012, May 10). Cooperative principle: The concept of implicature.

Retrived from http://awinlanguage.blogspot.co.id/2012/05/concept-of- implicature.html?m=1

Awalkar, A. (2010, October 10). What is the plot to the film pursuit of happyness?.

Retrived from https://www.quora.com/What-is-the-plot-to-the-film-Pursuit-of-Happyness

Dornyei, Z. (2007). Research methodology in applied linguistic. New York: Oxford

University Press

E103 Discussion (2009, March 25). Grice's maxims. Retrived from 
http://www.indiana.edu/ slavicgf/e103/class/2011_03_25/03_25.htm

Han, H. (2012, April 21). Grice's maxims. Retrieved from http://hancommtheory.blogspot.co.id/ 2012/04/grices-maxim.html

Khosravizadeh, P. and Sadehvandi, N. (2011). Some instances of violation and flouting of the maxim of quantity by the main characters (Barry and Tim) in Dinner for Schmucks. Retrived June, 09 , 2017 from $\mathrm{http} / / /$ www.academia.edu/1588301/Some_Instances_of_Violation_and_Flouting_of_the_Maxi m_of_Quantity_by_the_Main_Characters_Barry_and_Tim_in_Dinner_for_Schmucks

Heredia, S. (n.d.) Scene the pursuit of happyness (transcript). Retrieved March 15, 2017 from https://sites.google.com/site/mencionticinglesheredia/scene-the-pursuit-ofhappiness-transcript

Paltridge, B.(2006). Discourse analysis. London: Continuum.

Wayne, D. (2005, 6 May). Implicature. Retrieved from https://plato.stanford.edu/entries/implicature/\#Bib

Pursuit of happyness, the (2006) movie script. (n.d.). Springfield!!springfield!!. Retrieved $10 \quad$ march, 2017

http://www.springfieldspringfield.co.uk/movie_script.php?movie=pursuit-ofhappynessthe

Yule, G. (2014). The study of language. $5^{\text {th }}$ ed. America, New York: Cambrige

University Press. 